\title{
Conclusions: implications for tourism sustainability in natural, residential and mountain locations
}

\section{Introduction}

The set of articles in this issue broadens perspectives on sustainability in tourism both in terms of places and seasons. Our aim was to build on an earlier theme issue (Worldwide Hospitality and Tourism Themes, volume 10 number 2, 2018) which focused on mountain areas mostly during the winter season. This theme issue encompasses aspects of sustainability in natural spaces, second homes in rural and mountain locations and mountain tourism.

While the pandemic has and will have a significant and long-lasting impact on the tourism industry, it seems likely that new opportunities will emerge for natural, residential and mountain locations - in some cases, driven by the changes arising from the worldwide response to the COVID-19 virus. The objective of this issue was to identify current and pending challenges and offer solutions for destinations that are considering or actively seeking pathways to enhanced sustainability. The aim here is to summarize the key points arising from this collection of articles. In so doing, we identify and present some practical solutions relating to a set of eight themes that encapsulate the main issues and challenges for natural, residential and mountain locations.

\section{Theme 1: Perceived sustainability}

In her article, Mauri points out that sustainability has a complex meaning and that only few of its many dimensions are usually perceived by the general public. Ecotourism, nature tourism, wildlife tourism and rural tourism are the main categories that tourists spontaneously associate with sustainable tourism. While people tend to identify macro issues (such as food-waste) relating to sustainability that are difficult to resolve at an individual level, they are aware that their individual behaviour can contribute to environmental problem-solving, for example by using less plastic. However, to improve the level of understanding about sustainability among the general public and to promote behavioural change, education has a key role to play. Given this, there is a need for political action at national and local levels, to increase public awareness about sustainability, and its several dimensions. To reinforce this, civic office holders and others with public and visible roles, such as mayors, should be encouraged to adopt sustainable behaviours that will be seen as examples by the general public. Companies also have a role to play in sustainability education, by explaining more clearly and precisely the components of their products and services that are sustainable.

\section{Theme 2: Over-tourism is not only concerned with too many people in one place}

For some destinations, the flows of tourists exceed their hosting capacity. Many have images of the streets of Venice or Barcelona over-crowded with tourists. Some locals, instead of seeing tourism as an economic opportunity, complain about the growing social nuisance problem arising from too many tourists at peak holiday times in their cities. Whereas until recently, the problem was confined to popular tourist destinations, other locations such as Cinque Terre in Italy and Corsica in France, also suffer from overtourism. The two articles by Vegnuti (Cinque Terre) and Barthod-Prothade and Leroux (Corsica) describe the negative impacts of tourism on these places that are both characterised by a close relationship

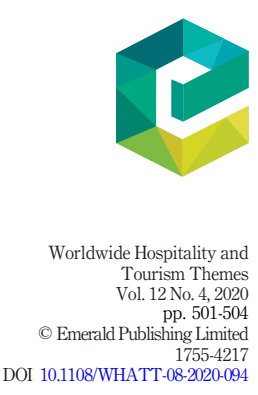


WHATT

12,4

502

between mountain and sea. Barthod-Prothade and Leroux identify different ways to limit and manage over-tourism in the Mare to Mares hiking trail. Besides the actions already implemented, they suggest that the different agencies involved in managing this trail, that is to say the managers and politicians whose responsibility it is to develop sustainable tourism in the mountains of Corsica, would benefit from a training course centred on the practical action that need to be taken. Further, that the content of the training should be based on the concept of territorial resilience, as well as on learning complex thinking and a systemic approach to planning for sustainability. This course could enable decision-makers to formulate a collective strategy aimed at creating resilient rural areas. The implementation of this strategy could be assessed using a sustainability grid specifically designed for mountain areas. Preserving biodiversity and coastal landscape should be part of this strategy too. In the case of Cinque Tierra, different actions will need to be taken to limit and manage over-tourism. Above all, there is a need for better coordination between the operators generating the tourist flows (cruises, bus operators, shipping companies, etc.). This improved coordination should lead to different agreements, such as the definition and carrying capacity of critical areas and the planning of arrivals and departures. Tourists staying in the region could be prioritized over day visitors. Finally, incentives should be considered for tourists who are willing to visit the destination during the off-season with new investment planning based on the need for environmental protection, with more equitable distribution of tourism revenues for those who demonstrate a commitment to this priority.

\section{Theme 3: Mountain areas should work on two key words: rarefied and uncontaminated}

The article by Bramanti and Ricci stresses that the production systems of the Alpine region and the peri-Alpine are mostly similar. Nevertheless, employment growth in the Alpine region is lower. To bridge this gap, tourism operators should take into consideration the unique attributes of the territory. The Alpine region should work on two dimensions related to sustainability rarefied and uncontaminated - to convert the weaknesses of the place into assets. For Italy to recover from the COVID-19 pandemic, public health emergency and economic crisis, the national political agenda will need to incorporate strategies aimed at increasing the cooperation between territories and between mountainous and urban areas. The health crisis requires provision for sustainable solutions such as ultra-wideband, upgrading to $5 \mathrm{G}$ and wi-fi networks, a reduction in energy consumption and the design of environmental services within territories. Having adequate infrastructures will allow public and private agencies in the Alpine territories to work more productively and to offer new digital services. It is also necessary to foster a form of cooperation between farmers, consumers, citizens and institutions to develop supportive relations between all tourism product stakeholders. The re-development of the village of Valliera, for instance, is based on the rebirth of an ancient traditional and unique local craft industry, that generated a social, economic and widespread "green" expansion. Further, establishments providing accommodation should encourage tourists to enjoy the diverse experiences of the destination, including local products, cultural events and treks, so that the destination becomes known as a vibrant living community rather than simply a holiday spot.

\section{Theme 4: Women entrepreneurs seem to be more sensitive to sustainability}

The article by Martini, Malacarne, Pederzolli Giovanazzi and Buffa shows how in rural and marginal areas of Trentino in Italy, women entrepreneurs more readily embrace sustainable behaviours than men. Many tourism, agriculture and artisan businesses are managed by women in this area. These organizations have a significant impact on local development, encouraging both other women and young people not to migrate. Women therefore play a crucial role in revitalizing these areas. Authenticity, experientiality, innovation and networks 
development are shown to be characteristics of female entrepreneurship. The businesswomen interviewed in this article had made decisions orientated towards social and environmental sustainability, through the way they designed their final products and selected their suppliers. This case illustrates the fact that with regard to sustainability, the individual capacity to build and animate networks of diverse stakeholders with different objectives is crucial. As women usually value relational skills in their daily work, they seem to have a more natural propensity to facilitate and maintain communication and cooperation processes within a network.

Theme 5: Children should be a target of sustainability education

Seraphin's article on the role of Mini Clubs in mountain resorts shows that children can have an impact on tourism sustainability if empowered. Mini Clubs, that were first created by Club Med in seaside resorts, can foster the sensitivity of children towards sustainability from a very young age by using a blend of educational and entertaining activities. Séraphin and Vo-Thanh (2020) suggest that education on sustainability for children in resorts, mini-clubs should cover all three domains of knowledge. Practically, Séraphin and Yallop (2019) promote the following actions for mini-clubs: they should have a local name and their activities should be embedded in the local culture; local products should be served and activities should be animated by locals. Eduction on sustainability for children can therefore help to address the many challenges that mountain tourism is facing and will face in the future. The good practices put in place in miniclubs could also be transferred to other tourism activities to foster in the future the sustainability of the industry. More tourism research also should focus on children as they are the tourists of tomorrow. The more they are sensitized to sustainability at a young age, the more likely they will be to adopt long-term sustainable behaviours as adults.

\section{Theme 6: Secondary residences are going through a process of uberization}

Secondary residences, once a significant component of life for those who own them and of the local community, are going through a process of commercialization and uberization. The article by Bachimon, Eveno and Gelvez shows how the commercialization of these second houses on a spectrum that ranges from lending to rentals to home exchange has turned secondary residences into an object of trade. The secondary residence is often the object of a material overinvestment that is symbolic and mental. The owners never quite leave their main place of residence when in the secondary one. The result is not two complementary spaces but a hybrid space made up of the interlocking of the two. Digitalization has made it easier to rent a secondary residence for a short period, using for instance the Airbnb platform, thus making it more an object of trade than a second home. From a sustainability perspective, the COVID-19 pandemic is likely to bring to a halt, the relatively rapid growth of short-term renting. Further, it may encourage owners to be more psychologically and physically invested in their secondary residence, and thereby to contribute more to the local economy.

\section{Theme 7: Tourists' decision to choose natural parks creates an ethical dilemma on the exploitation of animals}

Animals are one of the main assets that attract visitors to national parks. The article by Osti and Nava shows that tourists have to face an ethical dilemma when choosing these destinations. Indeed, they are curious and interested in having encounters with wild animals, but at the same time, they understand and are sensitive to the fact that the exploitation of animals has a significant impact on their well-being. Therefore, understanding the perceptions of visitors and their overall experience to take effective marketing decisions has become a necessity. The study by Osti and Nava was conducted in a natural park where animals can be seen only in the wild, which does not guarantee that visitors will see animals during their visit. Park managers have to decide whether to design 
WHATT

12,4

504

areas for observing animals in captivity, or leave the encounters as casual, more ad hoc opportunities. The results of this study reveal that wildlife was perceived as important and provided extra satisfaction only to some of the visitors. Nevertheless, experiencing too few encounters created dissatisfaction. In fact, those highly satisfied with the park were less sensitive to guaranteed observation of animals in specific places. These results demonstrate that while human-animal encounters can be an important factor for some visitors, the encounter should be encouraged in the most casual and natural way rather than in captivity.

Theme 8: The pandemic of COVID-19 may open new opportunities for mountain tourism The article by Séraphin and Dosquet illustrates the fact that the COVID-19 pandemic may open up new opportunities for mountain and rural destinations. In the post-COVID-19 context, second-home tourism and mountain tourism could indeed play the role of placebo for tourists who want to turn away from international travel and crowded cities. Mountain and rural destinations will therefore have to take this into account and manage changes in tourist behaviours, who are likely to become more sensitive towards sustainability. A resulting paradox may be that mountain destinations, by attracting more visitors eager to escape from city centres, will lose part of their attractiveness. These destinations will therefore need to find a balance between a growing volume of visitors with potentially negative social and environmental impacts, with the necessity to maintain a certain level of tourism income.

We hope that you found the different articles in this theme issue thought-provoking. Our aim was to bring together different perspectives on the complex issue of sustainability in natural, residential and mountain locations, from a French-Italian perspective. We identified and discussed some of the many challenges and issues that these destinations are facing. Added to this, the sudden and dramatic impact of the COVID-19 pandemic, would suggest that "sustainability" - in every sense - will become an even more pressing global priority. Further to this, we can anticipate that tourists will become even more sensitive to sustainability and this may help to build even stronger links between academic research and industry practitioners who must find and implement solutions to the myriad problems that the global tourism industry is facing. As we know from the partnership approach that this journal adopts, we can help and learn from each other. Finally, we would like to thank the European fund Interreg-Alcotra for fostering the cooperation between Savoie Mont Blanc University and Valley of Aosta University, which enabled us to organize conferences around the main theme of sustainable tourism in mountain areas. These conferences made it possible for us to gather together the French and Italian academics who contributed to this theme issue.

\section{Raphaël Dornier LEA, University Savoie Mont Blanc, Chambéry, France, and} Chiara Mauri School of Economics and Management, Carlo Cattaneo University, Castellanza, Italy

\section{References}

Séraphin, H. and Vo-Thanh, T. (2020), "Investigating the application of the principles for responsible management education to resort mini-clubs", The International Journal of Management Education, doi: 10.1016/j.ijme.2020.100377.

Séraphin, H. and Yallop, A. (2019), "An analysis of children' play in resort mini-clubs. strategic implications for the hospitality and tourism industry", World Leisure Journal, doi. 10.1080/ 16078055.2019.1669216. 